\title{
A PROSPECTIVE STUDY ON CLINICAL PROFILE OF STROKE PATIENTS ATTENDING IN A TERTIARY CARE HOSPITAL OF GUWAHATI, ASSAM.
}

KEY WORDS:

Cerebrovascular Accident,profile,haemorrhagic Stroke,stroke Infarct.

\section{Dr. Dhrubajyoti} Choudhury*

Department Of Neurology, GNRC Institute Of Medical Sciences , North Guwahati ,assam, -781030 *Corresponding Author

Dr. N. C. Borah

Dr. P. S. Deb

Dr. Amit Ranjan

Baruah

Dr. Kinzang

Wangda

\section{Dr. Jaiprakash}

Sharma

\section{Dr Pari Kemprai}

Department Of Neurology, GNRC Institute Of Medical Sciences , North Guwahati, assam, -781030

Department Of Neurology, GNRC Institute Of Medical Sciences , North Guwahati ,assam, -781030

Department Of Neurology, GNRC Institute Of Medical Sciences , North Guwahati ,assam, -781030

Department Of Neurology, GNRC Institute Of Medical Sciences , North Guwahati ,assam, -781030

Department Of Neurology, GNRC Institute Of Medical Sciences , North Guwahati,assam, - 781030

Department Of Neurology, GNRC Institute Of Medical Sciences , North Guwahati ,assam, - 781030

Cerebrovascular disease include most common devastating disorders :ischaemic stroke and haemorrhagic stroke. The incidence of cerebrovascular disease increases with age and the number of strokes is projected to increase as the elderly population grows.A stroke is the second leading cause of death worldwide. Some of the Indian studies have shown a stroke prevalence of $471.58 / 100000$ population.

OBJECTIVE: To study the clinical presentation, risk factors, neurological presentation, pattern of brain strokes, areas of

터 brain affected as per CT/MRI Brain scan findings in a newly admitted patients in GNRC Institute of Medical Sciences, North Guwahati,Assam.

METHODS: This is a prospective study included all new patients with stroke admitted in ICU and Ward under Neurology Department of GNRC institute of Medical Sciences ,North Guwahati,Assam, from 1st August,2018 to 31 st July ,2019.

RESULTS: The cerebrovascular strokes are more common in males (64.4\%) than females (35.6\%). Most common age group was 58-67 years (28.29\%). Most common clinical feature was hemiplegia (71.21\%). Most common risk factor was Hypertension $(89.51 \%)$ followed by diabetes mellitus(51.70\%). Most common type of stroke was haemorrhagic $(60.24 \%)$ followed by ischaemic $(39.75 \%)$. In stroke infarct most common involved areas were parietal (13.65\%). In hemorrhagic stroke most common site was basal ganglia (21.95\%) followed by thalamus (10.97\%).

CONCLUSION: Males were more commonly affected with cerebrovascular accident with hypertension was the most common risk factor among the stroke patients and most common type of stroke was haemorrhagic.

\section{INTRODUCTION:}

Among all the neurologic diseases of adult life,stroke or cerebrovascular disease rank first in frequency and importance.The common mode of expression of stroke is a relatively sudden occurrence of a focal neurologic deficit. ${ }^{3}$ Cerebrovascular disease include most common devastating disorders :ischaemic stroke and haemorrhagic stroke. A stroke is the second leading cause of death worldwide. The incidence of cerebrovascular disease increases with age and the number of strokes is projected to increase as the elderly population grows. ${ }^{4}$ Cerebrovascular disease has been defined as a rapidly developing signs of focal (or global) disturbance of cerebral function with symptoms lasting for $\geq 24$ hours, or leading to death with no apparent cause other than vascular origin. ${ }^{5}$ Some of the recent studies have elucidated the stroke pattern to considerable extent in our country with a prevalence rate 0471.58/100000 population ${ }^{(10,15)}$.

Hypertension, alcoholism, smoking \& dyslipidemia are commonest cause of stroke among the elderly ${ }^{(6,10)}$ where smoking, alcoholism, increased BMI, diabetes and hypertension are significantly associated with strokes among young people. ${ }^{(7,10)}$ Ischemic strokes account for $50 \%-85 \%$ of all strokes worldwide. ${ }^{8}$ Hemorrhagic strokes are due to subarachnoid hemorrhage or intracerebral hemorrhage, they account for $1 \%-7 \%$ and $7 \%-27 \%$ respectively of all strokes worldwide ${ }^{8}$

Stroke is becoming an important cause of premature death and disability in low-income and middle-income countries like India, largely driven by demographic changes and enhanced by the increasing prevalence of the key modifiable risk factors. As a result developing countries are exposed to a double burden of both communicable and noncommunicable diseases. The poor are increasingly affected by stroke, because of both the changing population exposures to risk factors and, most tragically not being able to afford the high cost for stroke care. Majority of stroke survivors continue to live with disabilities, and the costs of ongoing rehabilitation and long term-care are largely undertaken by family members, which impoverish their families ${ }^{(1,2)}$ Hence this study was done in our institute to know the profile, risk factors which covers all the population with low socioeconomic to higher economic class at a affordable cost of treatment to all patient with stroke.

\section{MATERIALS AND METHODS:}

This is a prospective study of all patients having the clinical diagnosis of cerebrovascular stroke and confirmed the 
diagnosis of stroke with specific investigations including CT scan brain/MRI brain admitted in the neurology ward and Intensive care unit (ICU) at GNRC Institute of Medical Sciences, North Guwahati,District:Kamrup,Guwahati, Assam, Pin;781030 between $1^{\text {st }}$ August,2018 to $31^{\text {st }}$ July,2019

\section{INCLUSION CRITERIA}

All patients above 18 years of age having clincal diagnosis and CT/MRI confirmed diagnosis of stroke.

\section{EXCLUSION CRITERIA}

Patient below 18 years of age.

Stroke due to trauma (head injury).

Patients CT/MRI reports not showing confirmed diagnosis.

Old stroke patients

Coagulation disorders, AV malformations.

The data obtained were analyzed using SPSS version 21.0 software. Results were expressed in frequencies and percentages.

\section{RESULTS:}

A total of 410 cases of stroke admitted in the neurology ward and intensive care unit (ICU) of GNRC institute of medical sciences, North Guwahati,Assam, who fulfill the inclusion and August,2018 to $31^{\text {st }}$ July,2019 were studied and evaluated for clinical and neurological presentation, risk factors, pattern of areas of brain affected by stroke.

Table 1: Frequency \& percentage of stroke patients according to the age groups.

\begin{tabular}{|l|l|l|}
\hline Age groups(years) & Frequency & Percentage (\%) \\
\hline $18-27$ & 2 & 0.48 \\
\hline $28-37$ & 15 & 3.65 \\
\hline $38-47$ & 69 & 16.82 \\
\hline $48-57$ & 97 & 23.65 \\
\hline $58-67$ & 116 & 28.29 \\
\hline $68-77$ & 89 & 21.70 \\
\hline $78-87$ & 16 & 3.9 \\
\hline$\geq 88$ & 6 & 1.46 \\
\hline Total & 410 & \\
\hline
\end{tabular}

As shown in the table -1 among the all 410 stroke patient age range was from 25 years to 91 years. In this study the youngest patient was 25 years and oldest was 91 years.

The incident of cerebrovascular accident (CVA) highest among the age group 58-67 years which comprises of $28.29 \%$ of all total stroke patient followed by $23.65 \%$ in $48-57$ years , $21.70 \%$ in $68-77$ years and lowest in the age group $18-27$ years.

Table 2: Gender wise distribution of stoke Patients.

\begin{tabular}{|l|l|l|}
\hline Gender & Frequency & Percentage (\%) \\
\hline Male & 264 & 64.4 \\
\hline Female & 146 & 35.6 \\
\hline Total & 410 & 100.0 \\
\hline
\end{tabular}

Out of total 410 cases, $264(64.4 \%)$ were males and 146 $(35.6 \%)$ were females as shown in Table 2 . The male to female ratio was 1.8:1. From the observation of Table no-2 it can be concluded that incidence of stroke is more common among male gender.

Table 3: Showing the frequency and percentage of Clinical features of stroke patients.

\begin{tabular}{|l|l|l|}
\hline $\begin{array}{l}\text { Predominant presenting } \\
\text { Clinical Features }\end{array}$ & Frequency* & Percentage (\%) \\
\hline Hemiplegia & 292 & 71.21 \\
\hline Speech involvement & 210 & 51.21 \\
\hline Faciobrachial palsy & 79 & 19.26 \\
\hline
\end{tabular}
exclusion criteria during the study period from $1^{\text {st }}$

\begin{tabular}{|l|l|l|}
\hline Altered sensorium & 196 & 47.80 \\
\hline Instability of gait & 178 & 43.41 \\
\hline Giddiness & 113 & 27.56 \\
\hline Vomiting & 64 & 15.60 \\
\hline Headache & 28 & 6.82 \\
\hline Coma & 35 & 8.5 \\
\hline $\begin{array}{l}\text { More than 2 clinical } \\
\text { Features }\end{array}$ & 160 & 39.02 \\
\hline
\end{tabular}

In Table 3 showing the most common clinical presentation was hemiplegia which $(71.21 \%)$ followed by speech involvement $(51.21 \%)$, altered sensorium $(47.80 \%)$,instability of gait(43.41\%), giddiness $(27.56 \%)$, coma was seen in $8.5 \%$ patients and more than 2 associated clinical features were seen in $39.02 \%$ patients.

Table 4: Frequency and percentage of risk factors for Strolke patients.

\begin{tabular}{|l|l|l|}
\hline Risk Factors & Frequency* & Percentage(\%) \\
\hline Hypertension & 367 & 89.51 \\
\hline Diabetes Mellitus & 212 & 51.70 \\
\hline Dyslipidemia & 165 & 40.24 \\
\hline Smoking & 78 & 19.02 \\
\hline Alcohol Intake & 53 & 12.92 \\
\hline Past H/O CAD & 16 & 3.90 \\
\hline Past H/O CVD & 17 & 4.14 \\
\hline RHD with Valvular disease & 2 & 0.48 \\
\hline
\end{tabular}

As shown in Table 4(multiple response) that most common risk factor was hypertension with $(89.51 \%)$ followed by diabetes $(51.70 \%)$, dyslipidemia $(40.24 \%)$, smoking (19.02\%), alcohol (12.92\%),H/O of previous(CVD) cerebrovascular accident $(4.14 \%), \mathrm{H} / \mathrm{O}$ coronary artery disease (3.90\%), RHD with valvular heart disease $(0.48 \%)$.

Table5: Genderwise distribution of differnet type of stroke

\begin{tabular}{|l|l|l|l|l|}
\hline \multirow{2}{*}{ Gender } & \multicolumn{4}{|c|}{ Type of Stroke } \\
\cline { 2 - 5 } & $\begin{array}{l}\text { Haemorrhagic } \\
\text { stroke }\end{array}$ & $\begin{array}{l}\text { Percentage } \\
(\%)\end{array}$ & $\begin{array}{l}\text { Ischaemic } \\
\text { Stroke }\end{array}$ & $\begin{array}{l}\text { Percentage } \\
(\%)\end{array}$ \\
\hline Male & 196 & 47.80 & 78 & 19.02 \\
\hline Female & 51 & 12.43 & 95 & 23.17 \\
\hline Total & 247 & 60.24 & 163 & 39.75 \\
\hline
\end{tabular}

As shown in Table 5 that $247(60.24 \%)$ patients suffered hemorrhagic stroke and $163(39.75 \%)$ patients suffered ischemic stroke. Out of 247 haemorrhagic stroke patients 196 were males and 51 were females, among the 163 ischemic stroke patients 78 were males and 95 were females. In this study showing male gender was important high risk factor for hemorrhagic stroke.

Table 6: Topographic distribution of Haemorrhagic Strolke Patients.

\begin{tabular}{|l|l|l|}
\hline \multirow{2}{*}{$\begin{array}{l}\text { Areas of Brain affected on } \\
\text { CT/MRI brain scan }\end{array}$} & Haemorrhagic Stroke \\
\cline { 2 - 3 } & Frequency & Percentage(\%) \\
\hline Parietal Lobe & 7 & 1.7 \\
\hline Frontal Lobe & 4 & 0.97 \\
\hline Temporal Lobe & 12 & 2.92 \\
\hline Occipital Lobe & 1 & 0.24 \\
\hline Basal Ganglia & 90 & 21.95 \\
\hline Thalamus & 45 & 10.97 \\
\hline Centrum Semiovale & 0 & 0 \\
\hline Ventricular & 26 & 6.34 \\
\hline Paraventricular & 1 & 0.24 \\
\hline Internal Capsule & 2 & 0.48 \\
\hline Lentiform Nucleus & 1 & 0.24 \\
\hline Caudate Nucleus & 4 & 0.97 \\
\hline Midbrain & 15 & 3.65 \\
\hline
\end{tabular}

www.worldwidejournals.com 


\begin{tabular}{|l|l|l|}
\hline Cerebellar & 23 & 5.60 \\
\hline Pons & 14 & 3.41 \\
\hline Medulla Oblogata & 2 & 0.48 \\
\hline Total & 247 & 60.24 \\
\hline
\end{tabular}

In table 6 showing the most common site of haemorrhagic stroke was basal ganglia $90(21.95 \%)$ followed by thalamus $45(10.97 \%)$, ventricular $26(6.34 \%)$ and cerebellar $23(5.60 \%)$.

\section{Table 7: Topographic distribution of Ischaemic Stroke} patients.

Areas of Brain affected on Ischaemic Stroke

\begin{tabular}{|l|l|l|}
\hline \multirow{2}{*}{ CT/MRI brain scan } & Frequency & Percentage (\%) \\
\hline Frontal Lobe & 56 & 13.65 \\
\hline Temporal Lobe & 12 & 2.92 \\
\hline Occipital Lobe & 4 & 0.97 \\
\hline Basal Ganglia & 9 & 2.19 \\
\hline Thalamus & 21 & 5.12 \\
\hline Centrum Semiovale & 3 & 0.73 \\
\hline Ventricular & 1 & 0.24 \\
\hline Paraventricular & 0 & 0 \\
\hline Internal Capsule & 6 & 1.4 \\
\hline Lentiform Nucleus & 2 & 0.48 \\
\hline Caudate Nucleus & 1 & 0.24 \\
\hline Midbrain & 1 & 0.24 \\
\hline Cerebellar & 8 & 1.95 \\
\hline Pons & 30 & 7.31 \\
\hline Medulla Oblogata & 1 & 1.95 \\
\hline Total & 163 & 0.24 \\
\hline
\end{tabular}

In table 7 showing the most common site of infarct parietal lobe $56(13.65 \%)$ followed by cerebellar $30(7.31 \%)$, basal ganglia $21(5.12 \%)$, frontal lobe $12(2.92 \%)$

\section{DISCUSSION :}

In this study of stroke patients the most common age group involved between 58-67 years followed by $48-57$ years, $68-77$ years and 38-47 years. It was observed that age group 58-67 years comprised of $28.29 \%$ of total stroke patient which closely correlates with study done by Maskey et al. ${ }^{9}$ and Vaidya et al ${ }^{10}$.

The male to female ratio was 1.8:1. Which correlates with study of Aiyar et al.11 (1.9:1). So it can be concluded that incidence of stroke is more common in male sex which correlates with study done by Aiyar et al, ${ }^{11}$, Vaidya et al ${ }^{10}$.

In this study most common clinical presentation was hemiplegia (71.21\%) which was followed by speech involvement $(51.21 \%)$. This observation closely correlates with the study done by Patne SV et al. ${ }^{[13]}$ hemiplegia $(55.28 \%)$ which was followed by speech involvement (13.82\%.) P. Chitrambalam et al. ${ }^{[12]}$ in which most common clinical presentation was hemiplegia (in $<45$ years was $93.3 \%$, and in $>45$ years was $89.2 \%$ ) followed by speech involvement (in $<45$ years was $43.3 \%$, and in $>45$ years $30.8 \%$ ).

In this study Hypertension (89.51\%) is the most common risk factor for stroke which correlates with the study done by Patne SV et al. $(48.78 \%)^{[13]}$, Abdu-Alrhaman Sallam et al ${ }^{[14]}(67 \%)$.

In this study diabetes mellitus was $51.70 \%$ which higher than the study done byVaidya et al ${ }^{[10]}$ where it was $9.3 \%$.

In this study most common type of stroke was haemorrhagic stroke $60.24 \%$ followed by ischaemic stroke $39.75 \%$ which was opposite to the study done by Vaidya et al ${ }^{[10]}$ where ischaemic stroke $75.1 \%$ and haemorrhagic stroke $22.8 \%$ and another study done by Aiyar et $\mathrm{al}^{[11]}$ in which infarction was in $70 \%$ and haemorrhagic stroke was $26 \%$.

In this study the most common site of haemorrhagic stroke was basal ganglia $90(21.95 \%)$ followed by thalamus $45(10.97 \%)$, ventricular 26(6.34\%) and cerebellar 23(5.60\%) which was similar to the study done by Vaidya et $\mathrm{al}^{[10]}$ and Aiyer et $\mathrm{al}^{[11]}$ from these study it has been concluded that in multiple haematoma site most common was ganglio-thalamic region of the brain.

In this study most common site of infarct (ischaemic stroke ) was parietal lobe $56(13.65 \%)$ followed by cerebellar $30(7.31 \%)$, basal ganglia $21(5.12 \%)$, frontal lobe $12(2.92 \%)$ which was correlates with the study done by Vaidya et $\mathrm{al}^{[10]}$ where common site of infarct was parietal (33.7\%), followed by frontal $(16.7 \%)$ followed by basal ganglia $(10.5 \%)$ and Eapen et $\mathrm{al}^{\mathrm{N},[6]}$ in which most common site was parietal (56\%) followed by basal ganglia \& frontal.

\section{CONCLUSION:}

From the above study it was found that the occurrence of stroke high among the age group between 58-67 years. This study showed male predominance in stroke cases and Hemorrhagic stroke was more than the stroke infarction. Males were more affected than females in hemorrhagic stroke where in stroke infarct patient's incidence was higher among female. Hypertension was amongst leading risk factors for both type of stroke. Most common clinical presentation was hemiplegia followed by speech involvement. Basal ganglia and thalamus are the most common part of the brain involved in haemorrhagic stroke and parietal lobe of the brain is the common part involved among ischaemic stroke patients.

\section{ACKNOWLEDGEMENTS:}

Sincerely thankful to Dr.Nomal Ch. Borah Sir,Chairman and founder ,Department of Neurology and Dr Partha Sarthi Deb Sir, GNRC Institute of Medical sciences, Guwahati,Assam, for continuous support and guidance \&Department of radiology for CT/MRI reporting ,Medical record department in charge for helping in data collection.

\section{CONFLICT OF INTEREST:}

There are no conflicts of interest.

ETHICAL CLEARANCE: Not Required.

\section{REFERENCES}

1. Bonita R, Beaglehole R. Stroke prevention in poor countries. Time for action. Stroke. 2007;38:2871-2.

2. International Journal of Advances in Medicine ,Patne SV et al. Int J Adv Med. 2016 Aug;3(3):666-670.

3. Adams and Victor's -Principles of Neurology Tenth Edition, Chap34,Cerebrovascular Diseases,Pag no-778.

4. Harrison's Principle Internal Medicine ,19th Edition ,Chap-446,Cerebr ovascular Diseases,Pag no-2559.

5. S. Hartona. Experiences from a multicenter stroke register: a preliminary report.BullWHO. 1976;54(5):541-53.

6. R. P. Eapen, J. H. Parikh, N.T. Patel. A study of clinical profile and risk factors of cerebrovascular stroke. Guj MedJ.2009;64(2):47-54.

7. Prasad Kameshwar, Singhal Kapil K. Stroke in young: an Indian perspective. Neurol India. 2010;58(3):343-50.

8. Feigin V, Lawes C, Bennet D, Barker Cello S, Parag V. Worldwide stroke incidence and early case fatality in 56 population based studies: a systematic review.Lancet Neurol. 2009;8(4):355-69.

9. Maskey A, Parajuli M, Kohli SC. A study of risk factors of stroke in patients admitted in manipal teaching hospital, Pokhara. Kathmandu Univ Med J (KUMJ).2011 Oct-Dec;9(36):244-7.

10. Chirayu V.Vaidya 1*, Drusty K. Majmudar2 . A retrospective study of clinical profile of stroke patients from GMERS Medical College and Hospital, Gandhinagar, Gujarat, International Journal of Clinical Trials | JulySeptember 2014 | Vol 1 | Issue 2:62-66.

11. Aiyar et al. A study of clinic-radiological correlation in cerebrovascular stroke (A study of 50 cases). Guj Med J. 1999 Mar;52:58-63.

12. P. Chitrambalam, Dipti Baskar, S. Revathy. A study on stroke in young and elderly in Rajiv Gandhi government general hospital, Chennai. Int J Clin Med. 2012;3:184-9.

13. Patne SV et al. Study of clinical profile of stroke patients in rural tertiary health care centre, Int J Adv Med.2016 Aug;3(3):666-670. 
PARIPEX - INDIAN JOURNAL OF RESEARCH | Volume-9 | Issue-1 | January - 2020 | PRINT ISSN No. 2250 - 1991 | DOI : $10.36106 /$ paripex

14. Abdul-Rahman Sallam, Khalid Al-Aghbari. The clinical profile of stroke: a Yemeni experience.J MedJ.2009;43(2):115-21.

15. S. K. Das, T. K. Banerjee, A. Biswas, D. K. Raut, C. S. Mukherjee, A. Chaudhari, et al. A prospective com-munity based study of stroke in Kolkata, India. Stroke. 2007;38(3):906-10. 